\title{
Assessment of Geodiversity as Tool for Environmental Management of Protected Nature areas in South-Eastern Latvia
}

\author{
Juris Soms \\ Daugavpils University, Faculty of Natural Sciences and Mathematics \\ Address: Parādes Street 1, Daugavpils, LV-5401, Latvia.
}

\begin{abstract}
The environmental management and nature protection policy in Latvia is mainly focused on biodiversity and protected species, while a geodiversity is 'forgotten side' of nature conservation work. Such situation is associated with an absence of a unified methodology for assessment of geodiversity, which is a shortened version of the term 'geological and geomorphological diversity'. The concept of geodiversity, as well the quantitative assessment of abiotic nature values is successfully used in the last decade. However, it has not yet been applied in Latvia for purposes of environmental management. Considering that the aim of this study was to apply the methodology described in the scientific literature for the assessment of geodiversity index in the GIS environment. The estimating of geodiversity was performed in two protected nature areas in south-eastern Latvia, i.e. nature reserve "Pilskalnes Siguldina" and geological nature monument "Adamovas krauja". The calculations of geodiversity index were done based on the components as geological data, landform units, morphogenetic processes, hydrological features and terrain roughness. The input data were processed, and numerical methods that analyze spatial data in regular grid format were applied in ArcGIS. The output data on the spatial variability of geodiversity index were reclassified in three classes in order to identify areas with low, medium and high geodiversity respectively. The assessment of geodiversity by quantifying the spatial distribution of geodiversity index can be used as a tool for environmental management of protected nature areas and spatial planning, allowing to identify places with high potential value and to prevent their transformations.
\end{abstract}

Keywords: geodiversity, environmental management, protected nature areas, geodiversity index, GIS.

\section{INTRODUCTION}

Nature heritage and diversity including both biotic and abiotic components is the essential renewable resource of Latvia because it determines the wide diversity of physical backgrounds for development and evolution of landscapes. Simultaneously the geological and geomorphological settings, combined with the variability of hydrological features, soils and topography are at the basis of the ecosystem services [1]. This concept that diversity of abiotic elements is fundamental for many key ecosystem functions and underpins a variety of the different types of ecosystem service has been approved by scientists around the world [2] - [5].

Despite that recognition of the importance of geological and geomorphological diversity at a policy level in Latvia remains low, and so far it is insufficiently integrated within the environmental management and protection planning processes. Hence nature conservation measures in Latvia is mainly focused on biodiversity and protected species [6], [7] while a diversity of elements of abiotic nature figuratively is 'forgotten side' of nature conservation work. This situation is caused by several reasons, e.g. lack of data, insufficient "geo-literacy" of most policy makers and planners, deficiency of standardized criteria and absence of a unified methodology for assessment of geodiversity.

The term 'geodiversity' is a shortened version of 'geological and geomorphological diversity' and in such meaning was first used in 1993 [8], following the Rio Summit or United Nations Conference on Environment and Development in 1992, where international agreement on the Convention on Biodiversity was accepted. Subsequently, the term of geodiversity has been defined as "the natural range (diversity) of geological (rocks, minerals, fossils), geomorphological (landform, processes) and soil features" [9]. Later, the definition was broadened to include also hydrological and topographic elements [10], [11] and currently it is interpreted by the scientific community as the abiotic equivalent of biodiversity. Similarly to biodiversity, geodiversity belongs to Earth's nature heritage or geoheritage which must be protected and preserved for next generations [9], [11], [12].

The concept of geodiversity is successfully used in the last decade in many countries for developing a new paradigm in geosciences, and as a new domain of research, protection of abiotic nature values and 
conservation of geoheritage [10], [14], [15]. However, despite widespread use and recognition of the concept, less progress has been achieved in assessment, quantification, and mapping of geodiversity. Although a review of the literature indicates that many scientists have acknowledged the relevance of geodiversity evaluation [9], [16], [17], hitherto comparatively small amount of studies have been dealt with the methodological issues.

Assessment and mapping of geodiversity and its elements within particular areas have been performed for a variety of purposes, and therefore approaches and methods of visualization are rather manifold. Though, regarding the content of study presented in this paper, in the literature there are examples of the application of geodiversity mapping for the quantitative assessment and geospatial representing of abiotic nature values. Such an approach is useful in order to provide efficient management and planning of the geoconservation in protected nature areas [18]- [21]. At the same time, it is also an additional tool which can be in principle used both in protected nature territories and outside them to identify areas with a high value of the abiotic nature elements. It, in turn, can serve for purposes of territorial planning and management, allowing to highlight potential sites of geotourism and to improve the conservation of geoheritage. However, the studies on geodiversity and its quantification have not yet been applied in Latvia for purposes of environmental management of protected nature areas. Considering that the aim of this study was to apply the methodology described in the scientific literature for the assessment of geodiversity index in the Geographic Information Systems (GIS) environment.

\section{MATERIALS AND METHODS}

The results presented in this paper are based on data obtained in the course of desk-based studies, field surveys and application of GIS tools of geospatial analysis and visualization of georeferenced data. The estimating of geodiversity was performed in two protected nature areas in south-eastern Latvia, i.e. nature reserve "Pilskalnes Siguldina" and geological nature monument "Adamovas krauja" (Fig. 1). The selection of both areas as model territories for research purposes was determined by the following reasons: (i) diversity of geological, geomorphological, hydrological features and processes located within a small area; (ii) presence of abiotic nature objects and formations which correspond to the status of national or local geological-geomorphological nature monuments and (iii) availability of data for development of highresolution digital elevation models (DEM).

Among others, one of the widely used methods for assessing the diversity of abiotic nature elements is based on calculations of geodiversity index (GI). Such an index indicates a geographic distribution of geodiversity on a particular territory, and at the same time implicitly provides the information for the evaluation of the variability of abiotic elements.

The most of the studies that apply GI as a quantitative and qualitative indicator of geological and geomorphological diversity are based on a concept originally published by Serrano and RuizFlaño [22] and later developed by other geoscientists [23]. For purposes of GI calculations and visualization of obtained data, the application of GIS appears the most appropriate analytical tool that can compute the spatial relationships among abiotic elements of geodiversity, hence allowing to define indices in numerical form [24]. Considering that, the ESRI ArcGIS 10.0 software package with Spatial Analyst and 3D Analyst extensions was selected for processing of data and assessment $o$ and visualization of GI values.

According to data given in the literature [20] the formula (1) for GI assessment is the following:

$$
G I=\frac{\left[\left(\sum_{\mathrm{i}=1}^{\mathrm{n}} V_{\mathrm{i}}\right)+\left(\sum_{\mathrm{i}=1}^{\mathrm{n}} G m_{\mathrm{i}}\right)\right]\left(\frac{S_{a}}{P_{a}}\right)}{\ln S_{a}}
$$

where $V_{\mathrm{i}}$ is variability of each abiotic element that contributes to GI assessment and has continuous character regarding its geospatial distribution, i.e. this element can be identified everywhere within the study site, covering entire area (e.g. soils, superficial sediments and rocks, topography); $G m_{\mathrm{i}}$ is each geomorphological, hydrological or geological feature (object or process) that contributes to GI assessment and has discrete character regarding its geospatial distribution, i.e. this element is discontinuous - either presented or not at any given spot within the study site (e.g. erratic boulders, springs, streams, morphogenetic processes); $S_{a}$ is surface area of the real topographic surface of DEM raster; $P_{a}$ is planimetric area of projection of DEM raster to horizontal plane.

The input data used to calculate $V_{i}$ in (1) include the following elements: geological data on the geographic distribution of Quaternary sediments; landform units; slope gradients and soils. The data on the geological substratum, geomorphology and soils were obtained during field surveys and manually digitised by ArcGIS tools. Each thematic layer in vector format was converted into ESRI format regular grid by cell resolution $1 \times 1 \mathrm{~m}$. Slope gradient data were calculated with the DEM using slope function in ArcGIS. Thereafter the geographic variability of the each continuous element was calculated in a moving window with a circle of radius $3 \mathrm{~m}$, applying neighborhood analysis and a focal statistics functions in ArcGIS.

The input data used to calculate $G m_{i}$ in (1) include the following elements: places of occurrence of morphogenetic processes, e.g. gully erosion, lateral erosion, landslides, accumulation; outcrops of 
Quaternary strata; erratic boulders; objects and formations corresponding to the status of national or local geological-geomorphological nature monuments, e.g. outcrop of interglacial peat, boulder pediments, outcrops of Devonian strata; hydrological objects - streams, lakes, springs; particular landforms - landslide cirques, gullies, glaciokarst kettles.

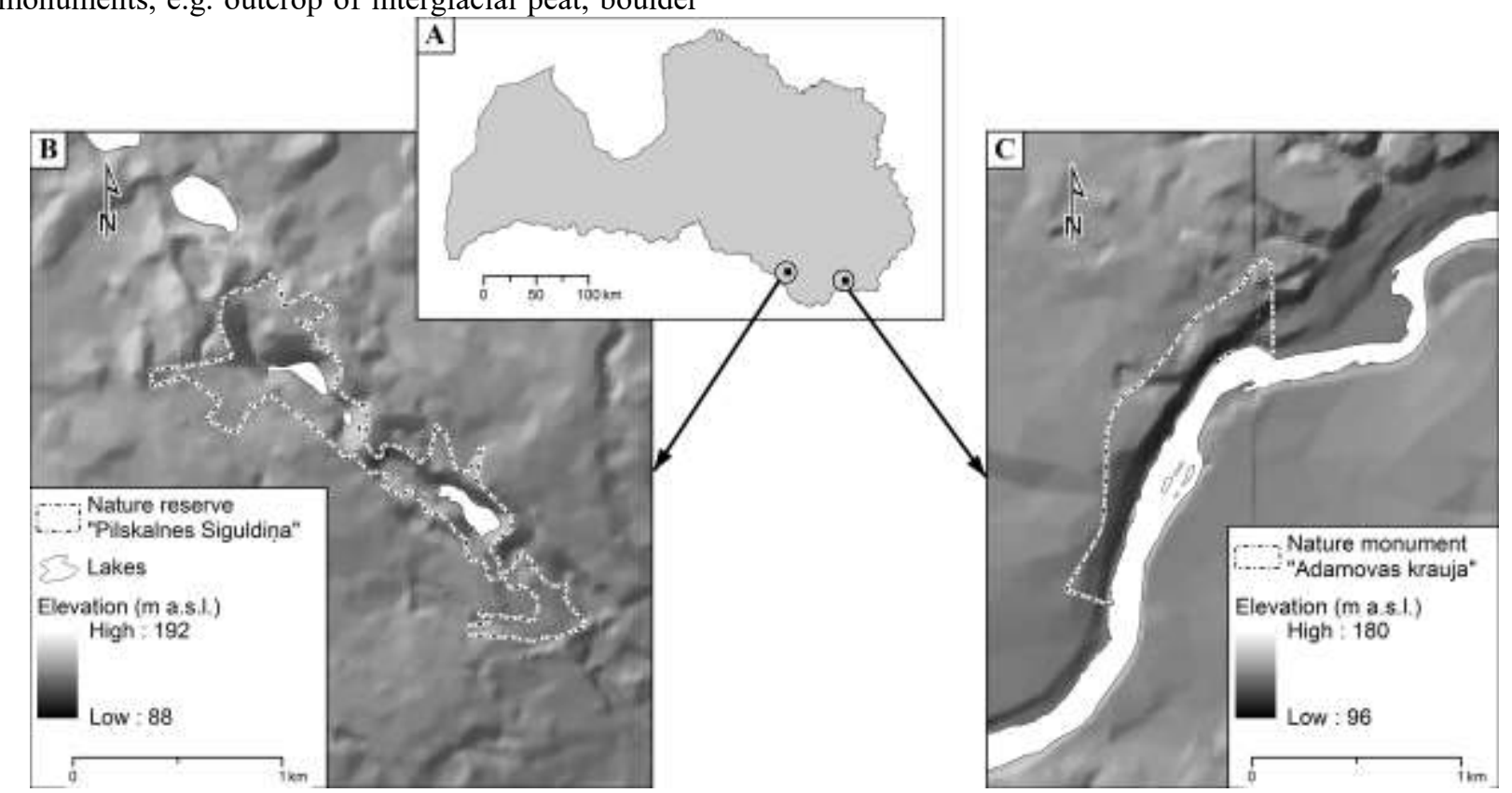

Fig. 1. Location of both protected nature areas in Latvia (A), showing relief of nature reserve "Pilskalnes Siguldina" (B) and nature monument "Adamovas krauja" (C) by a shaded DEM in the background.

The data on above-mentioned discontinuous geological and geomorphological elements of GI assessment were obtained during field surveys, and their position was recorded by high precision GPS TRIMBLE Pathfinder ProXRT. The GPS survey data were integrated into ArcGIS and converted to thematic layers. The data on hydrological elements were obtained from orthophoto maps and manually digitised at scale $1: 500$. Considering that some of the discontinuous elements regarding their geometric representation (i.e. points and polylines) in GIS environment have not area, before the spatial analysis of this kind of data the buffers were generated. The width of buffer zones was chosen according to requirements of national legislation and official regulations on protected nature objects, i.e. $10 \mathrm{~m}$. It allows to obtain features of polygon type. Thereafter $G m_{i}$ elements were merged and similarly to $V_{i}$ elements converted into ESRI format regular grid by cell resolution 1 x $1 \mathrm{~m}$. Subsequently, the geographic variability of the discontinuous elements was calculated.

For the obtaining of $S_{a}$ and $P_{a}$ data, highresolution DEM was developed, which was compiled both from topographic maps with contour interval 2 $\mathrm{m}$ (in a case of nature reserve "Pilskalne Siguldina") and airborne LiDAR data (in a case of nature monument "Adamovas krauja"). These both parameters enhance the role of terrain roughness in the assessment of geodiversity. In this case areas with high values of terrain roughness or ratio $S_{a} / P_{a}$ allow to find places where the amplitude of elevation alternates in a short distance. Usually, it indicates a higher intensity of geomorphological processes, a higher density of erosion network, and as a result higher values of geodiversity.

For quantification of terrain roughness, the $S_{a}$ and $P_{a}$ values for each cell of DEM grid were computed using the free tool "Surface Area and Ratio", which is developed for application in ArcGIS environment [25.] From these data topographic index was calculated as ratio $S_{a} / P_{a}$ by raster calculator tool. This ratio is used by geoscientists as an indicator of topographical irregularity and density of landforms per unit area in given territory [22].

Considering that each element produces a variety raster with a range of values different from the ranges obtained for the other abiotic element, raster data of each element of GI calculation were reclassified into five classes according to Jenks' algorithm and relative values were attributed to provide the compatibility of different data layers. It was done also for purposes of better perception of visualized geospatial data in ArcGIS environment and more accurate recognition of possible regularities on the geographic distribution of all $V_{i}$ and $G m_{i}$ variables.

After that the calculations of geodiversity index were done by applying the formula (1) in a procedure of spatial analysis, overlaying all the datasets and performing mathematical operations by raster calculator tool in ArcGIS. The output data and resulting maps on the spatial variability of geodiversity index were reclassified into five classes 
in order to identify areas with very low, low, medium, high and very high geodiversity respectively.

Finally, the nature management plans and supplementary maps of nature reserve "Pilskalnes Siguldina" and geological nature monument "Adamovas krauja" were examined and compared with the obtained maps of GI of both territories in order to evaluate the conformity of environmental management issues with the real situation and location of areas characterised by high geodiversity.

\section{RESULTS AND DISCUSSION}

The results obtained by assessment and mapping of GI and associated field studies carried out in nature reserve "Pilskalnes Siguldiņa" and geological nature monument "Adamovas krauja" indicate that the both areas have high geodiversity and geoheritage potential, respectively, a high concentration of abiotic nature elements of geoheritage significance. A variety of landforms, geological and hydrological objects, processes, diversity of other factors in terms of their morphology, origin, intensity, structure and intrinsic scientific or scenic/landscape value are identified within relatively small areas.

Analysis of data and mapping results allow distinguishing in both protected nature areas among others two main landforms, which are the most remarkable and important as geodiversity determinants. In the nature monument "Adamovas krauja" it is the Upper Daugava spillway valley but in nature reserve "Pilskalnes Siguldina" - subglacial tunnel valley. Both aforementioned geomorphological features actually underpin geodiversity in the sites under study, because occurrence and location of all other elements are directly associated with these negative medium to large scale landforms.

The Upper Daugava spillway valley, as the largest and most complex geomorphic unit in the nature monument and, in a broader context, also in the "Daugavas loki" nature park, should be included in the list of objects of geoconservation significance. This terraced valley was initially formed by glacial meltwater streams towards the end of Late Weichselian deglaciation and subsequently modified by fluvial processes in the Holocene. Despite the fact that currently the spillway valley is located within protected nature area, existing protection regulations provide conservation mainly of elements of biodiversity, but not the valley in its entirety. The spillway valley is a significant geosite, and at the same time regarding its scientific and paleogeographic significance, as well as and scenic and landscape values, it is one of the most remarkable river valleys in Latvia.

Regarding their contribution to the geodiversity, particularly due to high impact on the terrain roughness, among second grade, smaller scale geomorphological elements permanent gullies should be noted. In both nature areas gullies are widely distributed and deeply dissect the slopes of larger landforms, creating dense erosion network of temporal watercourses. Although the topographical irregularity determined by linear erosion network, in general, is an important contributing factor to the geodiversity in both areas; nevertheless, gullies itself as landforms within areas under study do not correspond to the status of objects of geoconservation significance. Their importance, in this case, should be noted in another context, i.e. gullies underpin the development of protected habitats of EU importance (Fig. 2) and hence contribute to the biodiversity of protected areas.

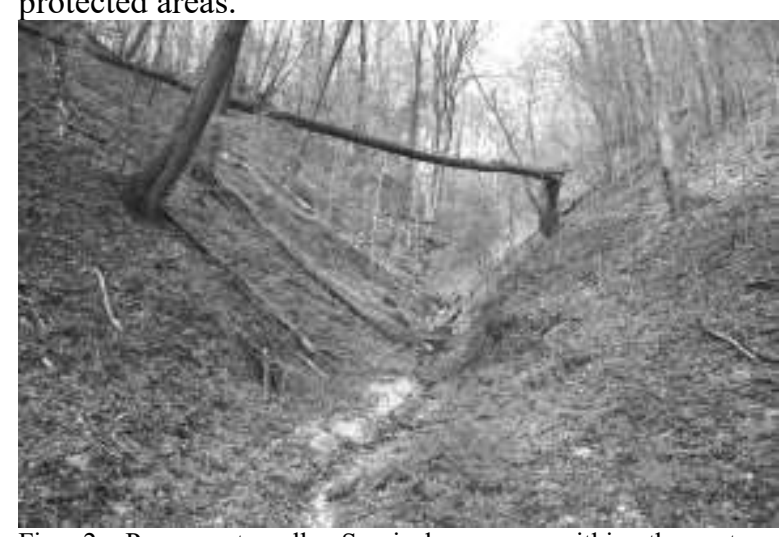

Fig. 2. Permanent gully Svarinsku grava within the nature monument "Adamovas krauja". Despite the comparatively low contribution to the geodiversity, such landforms have to be valued regarding biodiversity, e.g. due to the presence of protected habitats of EU of Habitats Directive like "9180 Tilio-Acerion forests of slopes, screes, and ravines".

All other geomorphological features as elements with intrinsic characteristics of spatial discontinuity, e.g. glaciokarst kettles, boulder pediments, places of groundwater outflow and springs, landslide cirques, etc. have no significant impact on the GI values. There is a twofold explanation for this established recognition: (i) one that these features have rare occurrence; hence they contribute to the geodiversity only in some particular locations; and, (ii) more feasible one that due to their small dimensions these features determines geodiversity indices only in some cells of maps; hence some tens of pixels even with high GI, in general, do not affect significantly the assessment of geodiversity at the scale used for elaboration of GI maps.

Analysis of the morphogenetic processes reveals that among others, development of mass movement processes is the most common ones both in nature reserve "Pilskalnes Siguldina" and geological nature monument "Adamovas krauja". Typically results of these processes can be observed as shallow and rotational landslides, earth-flows, and slumps on the slopes of river terraces and negative landforms (Fig. 3). 


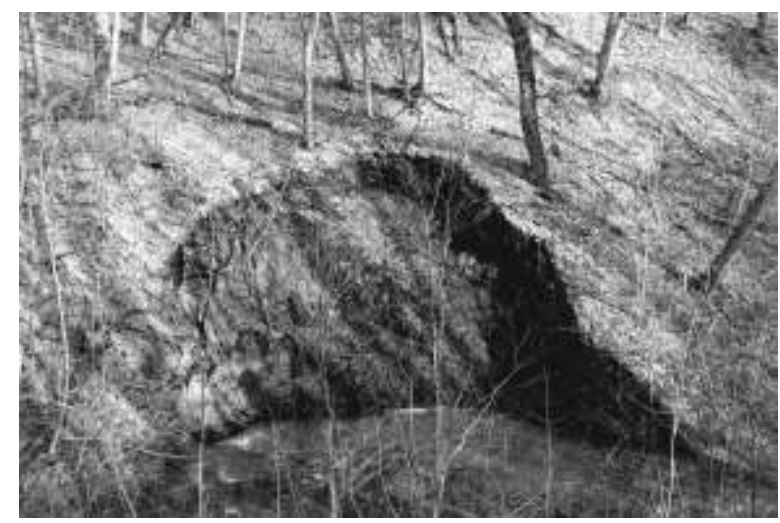

Fig. 3. Landslide development on the left slope of the river Dubupite

Valley, nature reserve "Pilskalnes Siguldina", as a typical example of morphogenetic processes contributing to the geodiversity.
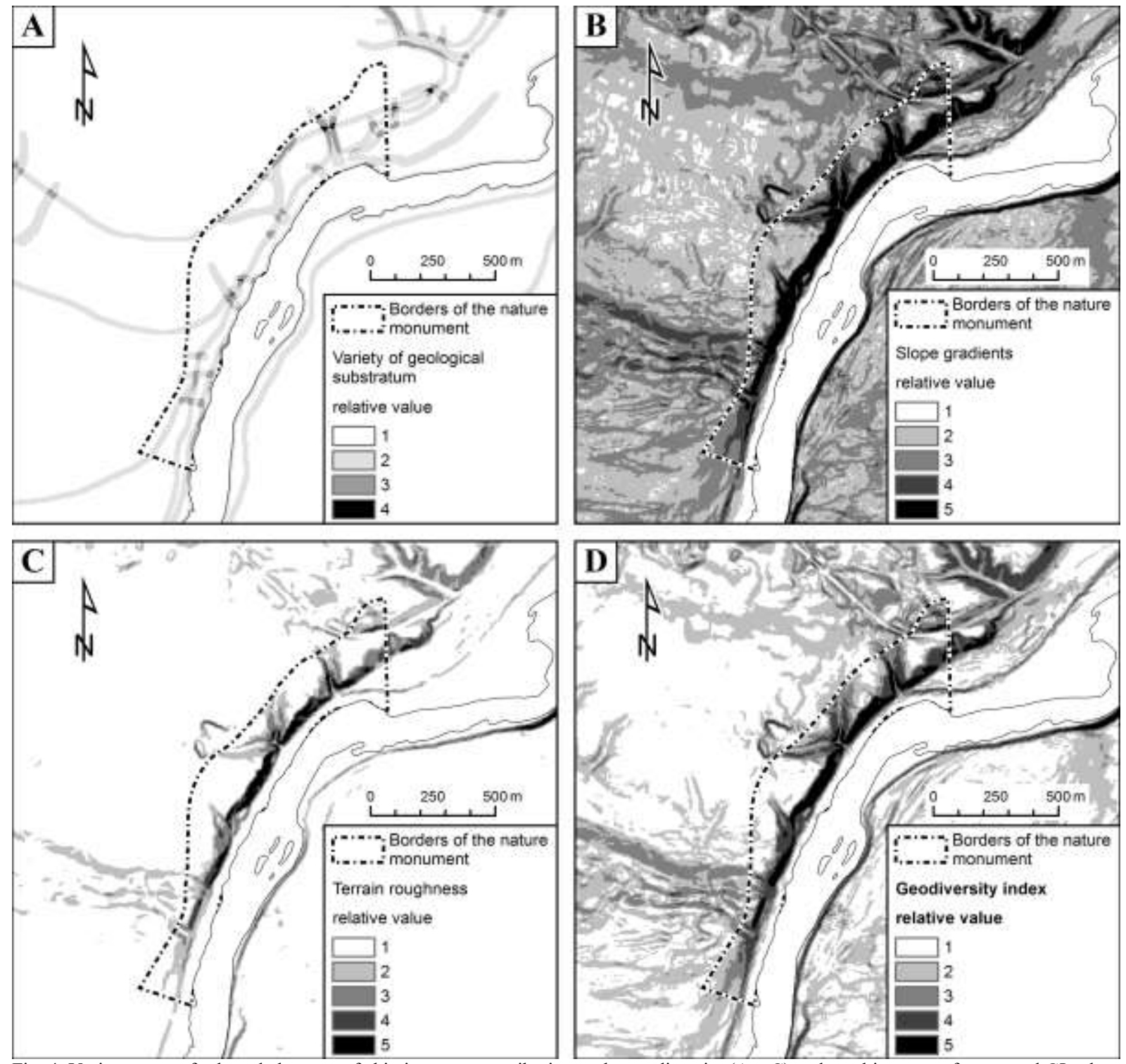

Fig. 4. Variety maps of selected elements of abiotic nature contributing to the geodiversity (A - C) and resulting map of computed GI values in grid format (D): an examples of nature monument "Adamovas krauja". Geographic distribution of geological factors (A), slope gradients (B) and terrain roughness indices (C) within the territory of the nature monument and areas adjacent to it. Geographic distribution of GI values, showing the results of quantification and assessment of geodiversity (D), colours indicate the variety, which increases from class 1 (the lowest values) to class 5 (the highest values). 
The wide distribution of mass movement processes is an excellent mark of the past and present a geological and geomorphological evolution of landscapes in protected nature areas indicating that development of abiotic nature elements and diversification of environment is still active. Therefore, the geomorphological evolution contributes to the increase of GI within the sites under study.

The relatively small geological features contributing to the geodiversity like outcrops of Quaternary strata, erratic boulders, objects and formations corresponding to the status of national or local geological-geomorphological nature monuments, e.g. outcrop of interglacial peat and outcrops of Devonian strata, similarly to the most of discontinuous geomorphological features have no significant impact on the GI values at a scale of mapping (Fig. 4). It is not consistent with the uniqueness and very high scientific values of these features hence indicating the discrepancy between the expectations based on the traditional notion and the computed values of GI. However, this fact has the same feasible explanation as in a case of geomorphological features, which is discussed previously.

The geospatial analysis of variability of abiotic elements with characteristics of spatial continuity, i.e. geographic distribution of Quaternary sediments, surface roughness, slope gradients and soils as determinants of GI reveals, that the topographic factors have the highest relative weight as determinants of geodiversity, hence to the great extent affecting the assessment of GI (Fig. 4).

Geostatistical analysis of the geographic distribution of the high and very high values of GI indicate that areas of high geoheritage significance have rather low proportion in comparison to lower ones (Fig. 4).

Finally, the examination of existing documents of the nature management plans and supplementary maps of both nature reserve "Pilskalnes Siguldina" and geological nature monument "Adamovas krauja" show that environmental management issues in general outlines conform to the location of areas characterised by high geodiversity. However, there are GI high-valued spots which are located outside the protected areas; hence they have not protection status.

\section{CONCLUSIONS}

The results of the studies presented in this paper permit to draw several important conclusions about the geodiversity of nature monument "Adamovas krauja" and nature reserve "Pilskalnes Siguldina", as well as about the assessment of geodiversity as a tool for environmental management of protected nature areas.
The most important abiotic elements with higher impact on the quantification of geodiversity are topographic factors, widely distributed landforms and morphogenetic processes, whilst many geomorphological and geological features with characteristics of spatial discontinuity are less significant.

The GI is the sum of the variety of each element taken into account in the process of raster calculation. However, in order to obtain a more reliable assessment of geodiversity, it is necessary to consider more complex mathematical apparatus instead of summing of inputs. It will allow taking into account also that features which have dimensions of only some meters or some tens of meters, but at the same time these features are the objects of geoconservation and geoheritage significance due to their uniqueness, paleogeographic, environmental or stratigraphic context. Otherwise, these discontinuous elements of geological and geomorphological diversity cannot be easily distinguished on the background patterns dependant mainly on the elements with characteristics of spatial continuity.

The obvious deficiency of the assessment of geodiversity by calculation and mapping of GI is that obtained results are dependent on scale, while in situ geodiversity of a particular location is scale independent.

Despite this imperfection, the method of GI quantification can be successfully applied for purposes of environmental management of protected nature areas, allowing to identify areas as targets for conservation and protection of geodiversity and geoheritage in Latvia. Hence such approach allows to come up with answers to key questions addressed by representatives of local authorities and decision makers to nature experts: what objects of abiotic nature, where and why should be protected.

\section{REFERENCES}

[1] R.S. De Groot, B. Fisher, M. Christie, J. Aronson, L. Braat, R. Haines-Young, I. Ring Integrating the ecological and economic dimensions in biodiversity and ecosystem service valuation. In: Kumar P.(Ed.), The Economics of Ecosystems and Biodiversity (TEEB): Ecological and Economic Foundations. London: Taylor \& Francis. 2010, pp. 9-40.

[2] M. Gray Other nature: geodiversity and geosystem services. Environmental Conservation 38. 2011, pp. 271-274.

[3] M. Gray Valuing geodiversity in an 'ecosystem services' context. Scottish Geographical Journal 128. 2012, pp. 177194.

[4] J.E. Gordon, H.F. Barron, J.D. Hansom, M.F. Thomas Engaging with geodiversity - why it matters. Proceedings of the Geologists' Association 123. 2012, pp.1-6.

[5] C.C.D.F. van Ree, P.J.H. van Beukering. Geosystem services: A concept in support of sustainable development of the subsurface. Ecosystem Services 20. 2016, pp. 30-36.

[6] E. Muižniece, J. Soms. A geomorphological approach for enhancing environmental management and conservation of landforms as protected nature objects in the Upper Daugava spillway valley. In: Proceedings of the $10^{\text {th }}$ International Scientific and Practical Conference "Environment. Technology. Resources". Vol.2. 2015, pp.225-231. 
[7] Soms J., Muižniece E. Landforms and Geological Objects of Geoconservation Significance in the Nature Park „Daugavas loki”, Latvia. In.: Abstracts of the VIII International ProGEO Symposium 'Geoconservation Strategies in a Changing World'. Reykjavik, Iceland. ProGEO. 2015, pp.98-99.

[8] C. Sharples. A Methodology for the Identification of Significant Landforms and Geological Sites for Geoconservation Purposes. Report to Forestry Commission, Hobart, Tasmania. 1993, 31 pp.

[9] M. Gray Geodiversity: Valuing and Conserving Abiotic Nature. Chichester: John Wiley \& Sons. 2004, 448 pp.

[10] M. Gray. Geodiversity: developing the paradigm. Proceedings of the Geologists' Association 19. 2008, pp. 287-298.

[11] M. Gray. Geodiversity: Valuing and Conserving Abiotic Nature, $2^{\text {nd }}$ ed. Chichester: Wiley-Blackwell. 2013, 508 pp.

[12] ProGEO. Conserving our Shared Geoheritage - A Protocol on Geoconservation Principles, Sustainable Site Use, Management, Fieldwork, Fossil and Mineral Collecting. 2011, $10 \mathrm{pp}$.

[13] L. Erikstad. Geoheritage and geodiversity management - the questions for tomorrow. Proceedings of the Geologists Association 124. 2013, pp.713-719.

[14] E. Reynard, P. Coratza. Geomorphosites and geodiversity: a new domain of research, Geographica Helvetica 62. 2007, pp. $138-139$.

[15] M. H. Henriques, A.O. Tavares, A.L.M. Bala. The geological heritage of Tundavala (Angola): An integrated approach to its characterisation. Journal of African Earth Sciences 88. 2013, pp. 62-71.

[16] E. Reynard, M. Panizza. Geomorphosites: definition, assessment and mapping. Géomorphologie: relief, processus, environnemen 3. 2005, pp. 177-180.
[17] P. Pereira, D.I. Pereira, M.I.C. Alves. Geomorphosite assessment in Montesinho Natural Park (Portugal). Geographica Helvetica 62. 2007, pp.159-168.

[18] R. Pellitero, M.J. González-Amuchastegui, P. Ruiz-Flanõ, E. Serrano. Geodiversity and geomorphosite assessment applied to a natural protected area: the Ebro and Rudron gorges Natural Park (Spain). Geoheritage 3. 2011, pp.163-174.

[19] E. Serrano, J.J. González-Trueba. Assessment of geomorphosites in natural protected areas: the Picos de Europa National Park (Spain). Géomorphologie: Relief, Processus, Environnement 3. 2005, pp. 197-208.

[20] L. Melelli Geodiversity: a new quantitative index for Natural protected areas enhancement. GeoJournal of Tourism and Geosites 13. 2014, pp. 27-37.

[21] A.M. Martinez-Graña, J.L. Goy, C. Cimarra. 2D to 3D geologic mapping transformation using virtual globes and flight simulators and their applications in the analysis of geodiversity in natural areas. Environmental Earth Sciences 73. 2015, pp. 8023-8034.

[22] E. Serrano, P. Ruiz-Flaño. Geodiversity: a theoretical and applied concept. Geographica Helvetica 62. 2007, pp.140147.

[23] Z. Zwoliński, A. Najwer, M. Giardino. Methods of geodiversity assessment and theirs application. Geophysical Research Abstracts Vol. 18, EGU2016-15434, 2016.

[24] L. Melelli, M. Floris. A new Geodiversity Index as a quantitative indicator of abiotic parameters to improve landscape conservation: an Italian case study. Geophysical Research Abstracts Vol. 13. EGU2011-13881, 2011.

[25] J.S. Jenness. Calculating landscape surface area from digital elevation models. Wildlife Society Bullettin 32. 2004, pp.829839. 